This document was prepared in conjunction with work accomplished under Contract No. DE-AC09-96SR18500 with the U. S. Department of Energy.

\title{
DISCLAIMER
}

This report was prepared as an account of work sponsored by an agency of the United States Government. Neither the United States Government nor any agency thereof, nor any of their employees, makes any warranty, express or implied, or assumes any legal liability or responsibility for the accuracy, completeness, or usefulness of any information, apparatus, product or process disclosed, or represents that its use would not infringe privately owned rights. Reference herein to any specific commercial product, process or service by trade name, trademark, manufacturer, or otherwise does not necessarily constitute or imply its endorsement, recommendation, or favoring by the United States Government or any agency thereof. The views and opinions of authors expressed herein do not necessarily state or reflect those of the United States Government or any agency thereof.

This report has been reproduced directly from the best available copy.

Available for sale to the public, in paper, from: U.S. Department of Commerce, National Technical Information Service, 5285 Port Royal Road, Springfield, VA 22161, phone: (800) 553-6847, fax: (703) 605-6900

email: orders@ntis.fedworld.gov

online ordering: http://www.ntis.gov/help/index.asp

Available electronically at http://www.osti.gov/bridge

Available for a processing fee to U.S. Department of Energy and its contractors, in paper, from: U.S. Department of Energy, Office of Scientific and Technical Information, P.O. Box 62, Oak Ridge, TN 37831-0062,

phone: (865)576-8401,

fax: (865)576-5728

email: $\underline{\text { reports@ adonis.osti.gov }}$ 
WSRC-MS-2002-00558

\title{
Separation Membrane Development (Separation Using Encapsulated Metal Hydride)
}

\author{
L. Kit Heung \\ Westinghouse Savannah River Company \\ Aiken, SC 29808, USA
}

Goals and Objectives

The goal of this work is to develop an efficient hydrogen separation process based on a new type of composite material. There are two main objectives: The first is to produce a sol-gel encapsulated metal hydride packing material that will a) absorbs hydrogen selectively and reversibly, b) not break down to fines, and c) be resistant to reactive impurities. The second objective is to evaluate the hydrogen separation properties of these composite samples in a laboratory scale separation column.

\section{Status of Progress}

Several composite samples have been produced and two of them tested in a small-scale separation column for separating hydrogen from a hydrogen-nitrogen mixture. Separation tests using other gaseous mixtures have been planned will be conducted soon.

\section{Background}

For a hydrogen economy to become a reality, hydrogen production will have to be greatly increased from what it is today. According to U.S. DOE 1994 fuel use numbers, U.S. household transportation fuel use is a hydrogen equivalent of 0.55 billion $\mathrm{lb} / \mathrm{day}$. This is about 6 times the total U.S. hydrogen use of 0.1 billion $\mathrm{lb} /$ day today. Where will all the hydrogen come from? Definitive answer to this question is not yet known. One probable answer may be that hydrogen must come from multiple sources. These sources will include renewable (solar, wind, hydro, biomass and etc.) and non-renewable (fossil, nuclear and etc.) One sure thing is that hydrogen will have to be recovered from all kinds of gas streams. Many of them will contain low levels of hydrogen and undesirable impurities. Today's hydrogen recovery processes include the most commonly used pressure swing adsorption process, the cryogenic process, and the membrane process. Their use for low concentration feeds and to reach high recovery are not efficient. New hydrogen recovery process is still needed. This work is targeted at a new hydrogen recovery process that will be suited for hydrogen recovery from low concentration gas streams.

\section{Metal Hydrides for Hydrogen Absorption}

When hydrogen content in a feed stream is high (more than about $50 \%$ ), it is efficient to adsorb the impurities separating them from the hydrogen. This is the principle of the pressure swing adsorption process. When the hydrogen concentration is low (less than about $50 \%$ ). It will be more efficient to absorb the hydrogen instead. However, a practical absorbent for hydrogen is not yet available. In the 1970s metal hydrides became a very well known group of material for they absorb hydrogen reversibly at moderate conditions. One example is $\mathrm{LaNi}_{4.25} \mathrm{Al}_{0.75}$ :

$$
2 \mathrm{LaNi}_{4.25} \mathrm{Al}_{0.75}+5 \mathrm{H} 2 \leftrightarrow 2 \mathrm{LaNi}_{4.25} \mathrm{Al}_{0.75} \mathrm{H}_{5}
$$


Each bulk liter of this material can absorb up to 18 moles of hydrogen reversibly. The hydrogen can be absorbed and desorbed by changing the hydrogen pressure, the temperature or both. This group of material would have been well suited for hydrogen recovery from low concentration streams if not for two practical problems. Metal hydrides in general breaks down to fines after repeated hydrogen absorption and desorption. The fines are in the micron range that makes them very difficult to use in separation columns. Metal hydrides are sensitive to reactive impurities like oxygen and carbon monoxide. Levels at hundredth of a fraction can render them inactive toward hydrogen. Past efforts to deal with these problems can be represented by the works of Sandrock et al [1] and Suda et al [2].

\section{Encapsulate Metal Hydride}

In this work metal hydride particles are encapsulated in a porous silica matrix to form a composite material. The composite is break up to granules of desired size for packing separation columns. Each granule is a matrix of porous silica with metal hydride particles uniformly distributed in it. The porous matrix are strong so that hydrogen absorption and desorption of the metal hydride particles does not cause breakage. The porosity of the matrix permits hydrogen to reach the metal hydride particles but prevents the larger size impurity molecules to penetrate. The composite granules can therefore withstand hydrogen absorption/desorption without generating fines and tolerate reactive impurities.

The fabrication of encapsulated metal hydride involves 3 main steps. 1) Break metal hydride to fine particles and stabilize the fines for handling in open air. 2) Encapsulate the metal hydride particles in silica with the sol-gel method. 3) Treat the composite with heat to obtain desired strength and porosity. The steps are illustrated in Figure 1 below. Micrographs of the composite is shown in Figure 2.

1. Break metal hydride former to small particles

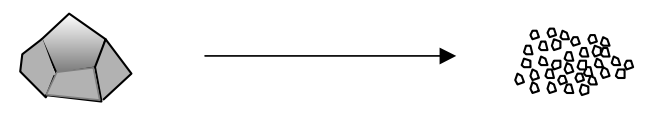

\section{Encapsulate the particles in a porous silica matrix}

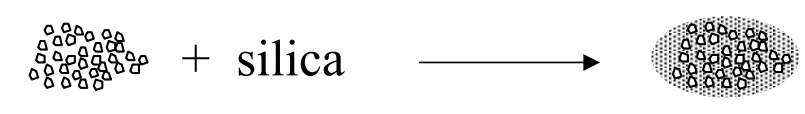

\section{Heat treatment to desired matrix porosity}

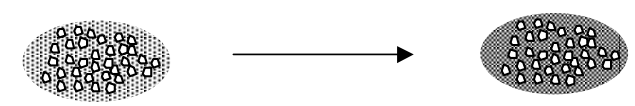

Figure 1. Metal Hydride Encapsulation 


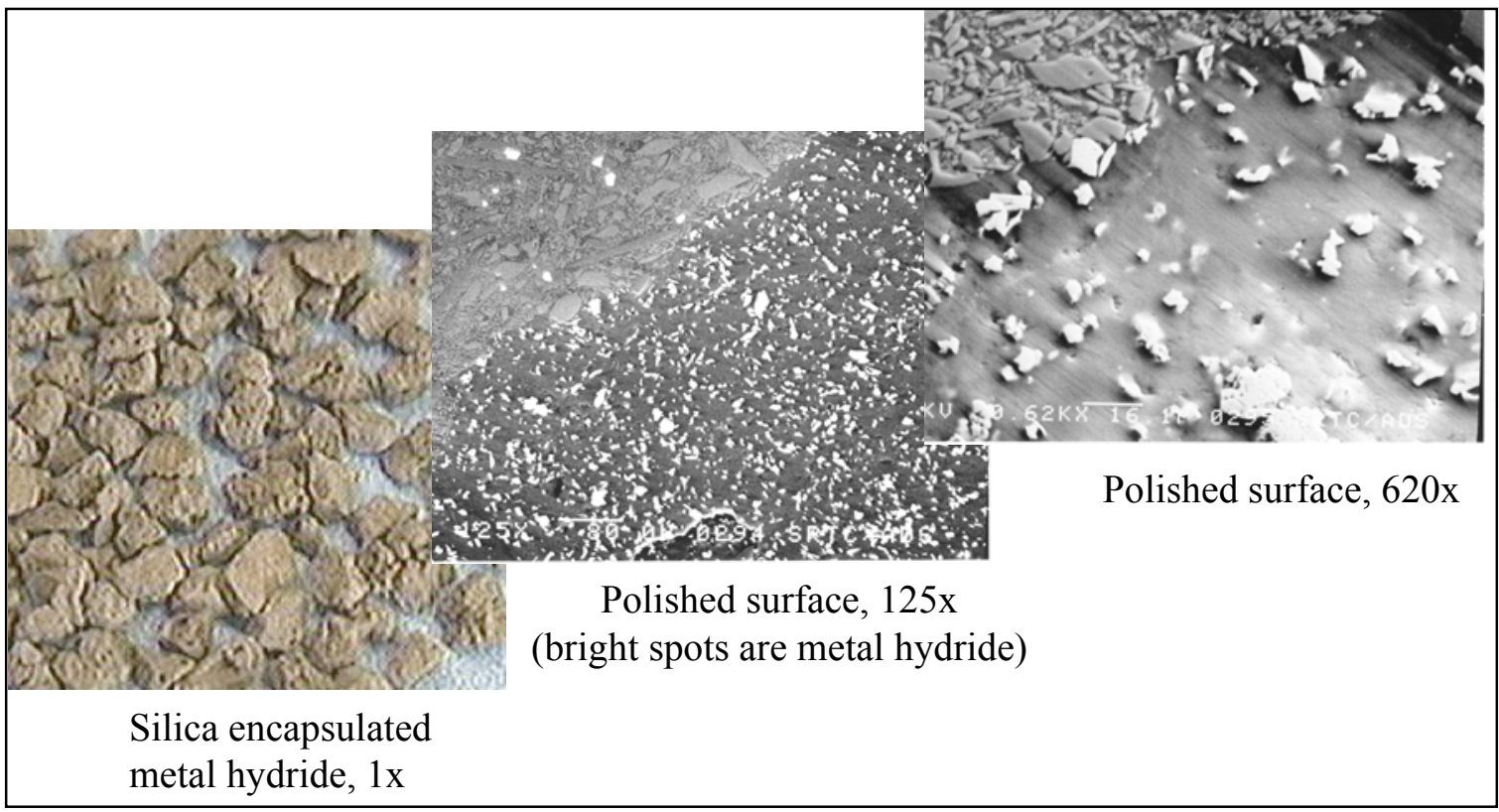

Figure 2. Silica encapsulated metal hydride

Hydrogen Absorption Property of Encapsulated Metal Hydride

Samples of encapsulated $\mathrm{LaNi}_{4.25} \mathrm{Al}_{0.75}$ were tested for hydrogen absorption in a gas manifold with hydrogen from a know volume. The results showed that the encapsulated sample was easier to activate than the non-encapsulated metal hydride. The hydrogen absorption capacity of the encapsulated metal hydride did not change significantly. The encapsulated sample also retained its activity better than the non-encapsulated sample after exposure to air. After repeated absorption/desorption the granules did not generate fines as metal hydride did. See Figures 3 and 4, and Table 1.

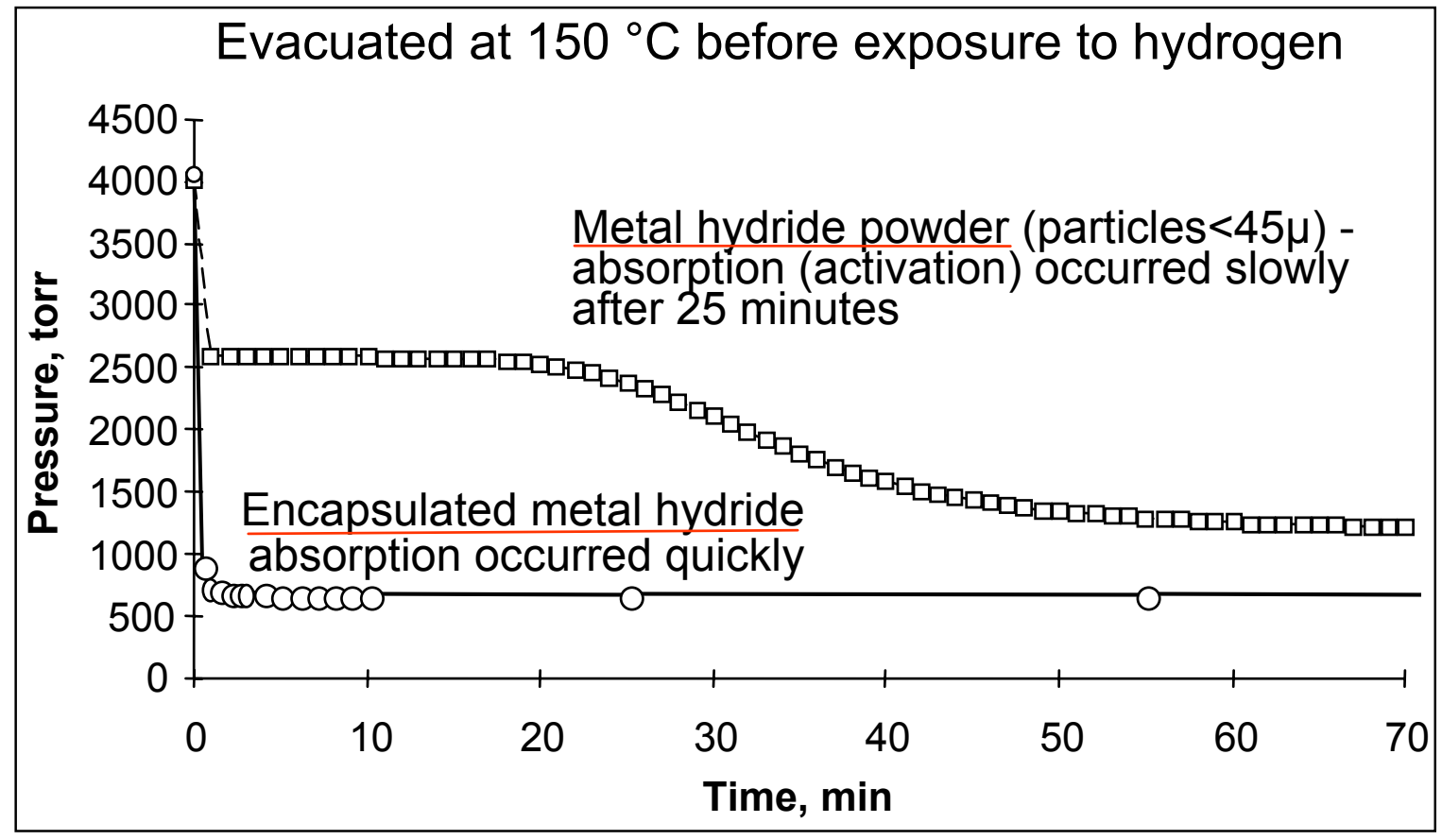

Figure 3. Hydrogen absorption during the first hydrogen exposure. 
Table 1. Hydrogen absorption capacity of encapsulated metal hydride.

\begin{tabular}{|lcc|}
\hline \multicolumn{1}{|c|}{ Sample } & $\begin{array}{c}\text { Wt \% Metal Hydride } \\
\left(\text { LaNi4.25 } \mathrm{Al}_{0.75)}\right.\end{array}$ & $\begin{array}{c}\text { Hydrogen Capacity } \\
\mathrm{H} / \mathrm{M}\end{array}$ \\
\hline Pure LaNi4.25 $\mathrm{Al}_{0.75}$ & 100 & 0.76 \\
$\begin{array}{l}\text { Silica embedded LaNi4.25 } \mathrm{Al}_{0.75} \text { by the } \\
\text { sol-gel method }\end{array}$ & 23.8 & 0.76 \\
$\begin{array}{l}\text { Silica embedded LaNi4.25 } \mathrm{Al}_{0.75} \text { by the } \\
\text { fumed silica method }\end{array}$ & 27.7 & 0.77 \\
$\begin{array}{l}\text { Silica embedded LaNi4.25 } \mathrm{Al}_{0.75} \text { by the } \\
\text { fumed silica method } \\
\begin{array}{l}\text { Silica embedded LaNi4.25Al0.75 by the } \\
\text { fumed silica method }\end{array}\end{array}$ & 51.4. & 0.72 \\
\hline
\end{tabular}

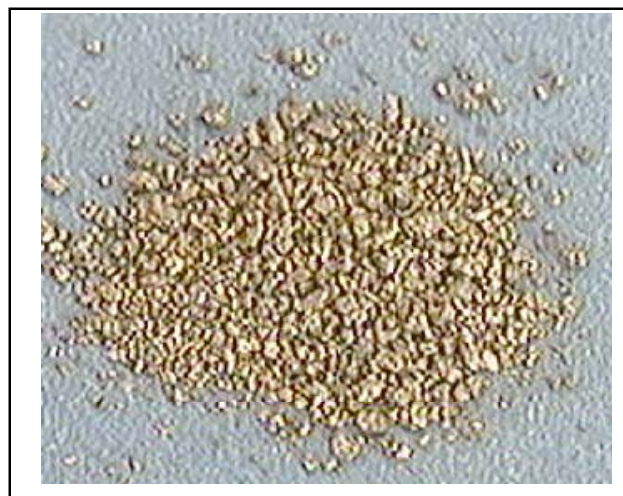

$\sim 0.5 \mathrm{~mm}$ particles
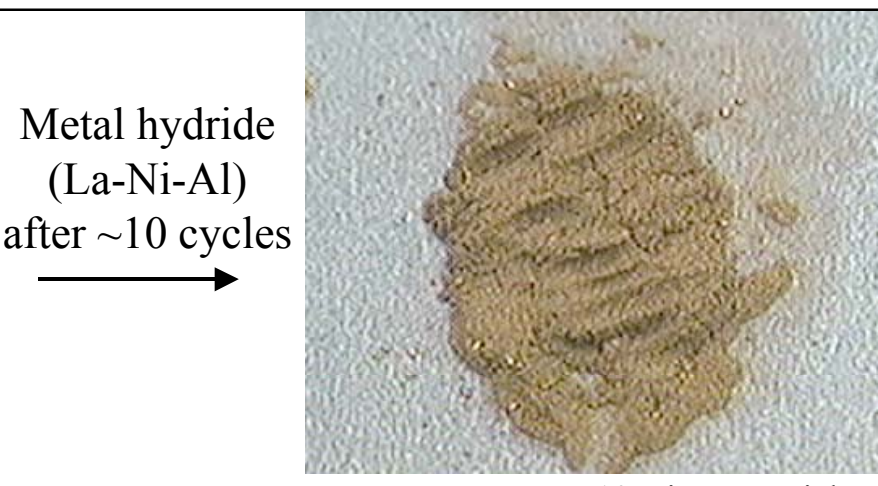

$\sim 10$ micron particles

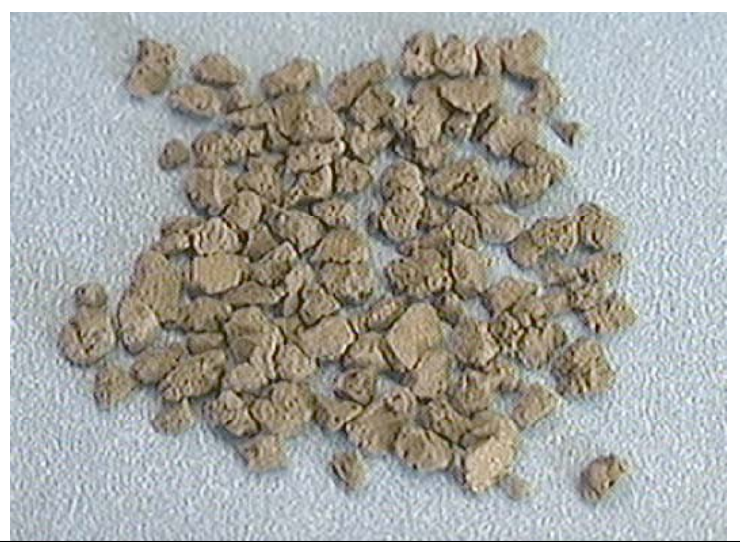

Encapsulated metal hydride after $\sim 100$ cycles

$\sim 1.5 \mathrm{~mm}$ particles

Figure 4 Granules of encapsulated metal hydride did not generate fines 


\section{Hydrogen recovery from a flowing stream}

A laboratory scale separation apparatus was set up for testing the hydrogen separation properties of encapsulated metal hydride samples. The apparatus consists of a gas manifold, a packed column and a thermal conductivity detector (TCD). The gas manifold comprises supplies of hydrogen, nitrogen, methane, carbon dioxide and carbon monoxide. Mass flow controllers are used to generate gaseous mixtures to feed the separation column. The column is a U-shape $3 / 4^{-}$ inch diameter, 6-inch long stainless steel tube, packed with encapsulated metal hydride granules. On the outlet side of the column, a pressure-regulating valve keeps the pressure in the column at a constant. A side stream is directed to the TCD for measuring the hydrogen concentration. A top-open furnace and a water bath are use to heat or cool the column when needed. Photographs or the manifold and column are shown in Figures 5.

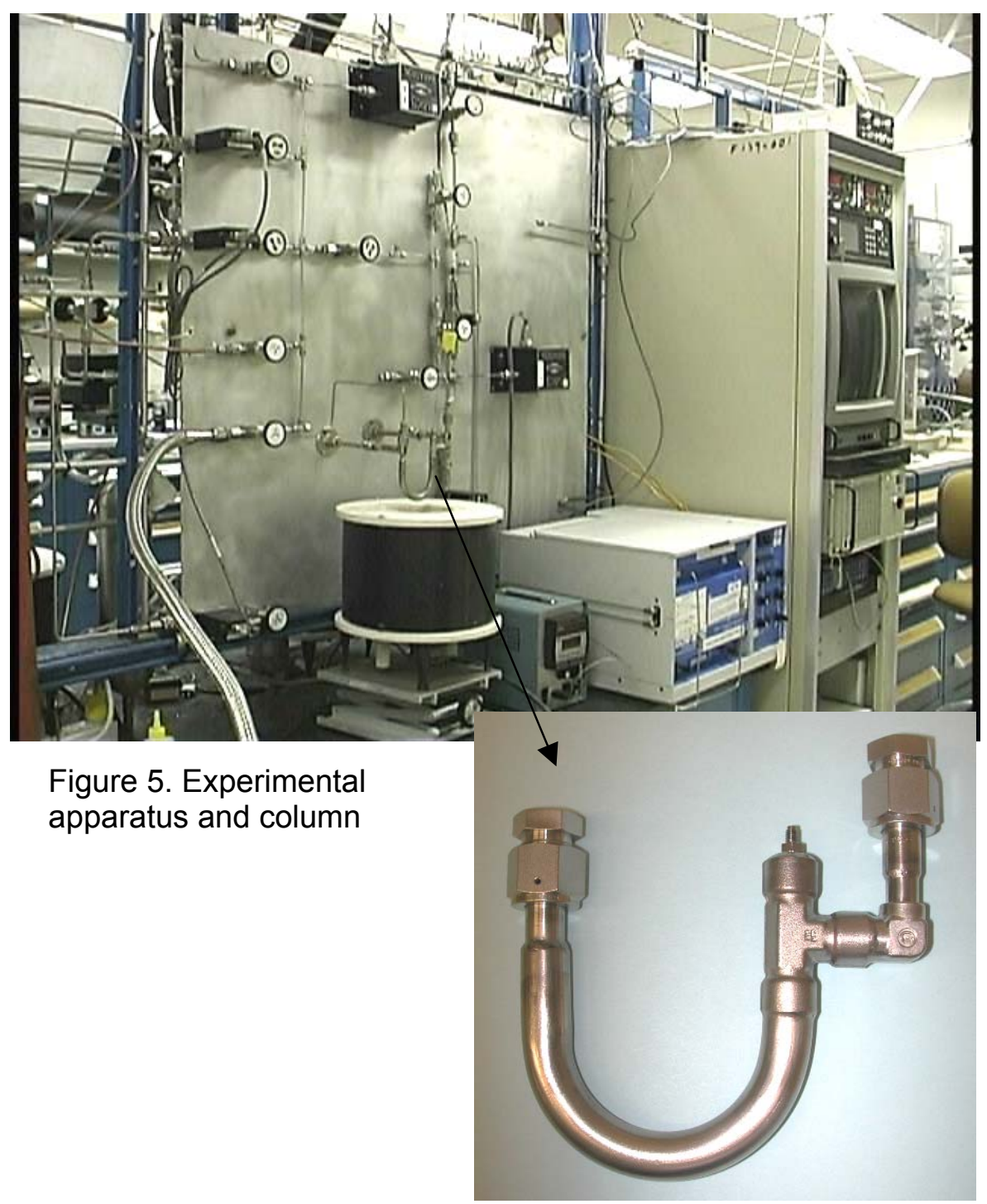

A typical test involves a hydrogen absorption step and a regeneration step. In the absorption step, hydrogen and carrier gases at target rates are jointed to form a feed stream to enter the column. The hydrogen is absorbed and the carrier gas is left passing through the column. As 
the absorption capacity of the packing material at the inlet end is saturated gradually, an absorption front is developed in the column. The absorption front is an inverse-S shaped concentration profile of hydrogen in the gas phase. This absorption front exits the column when the packing material is completely saturated. The hydrogen concentration measured by the TCD will show the absorption front to be an S-shaped curve of hydrogen concentration versus time. This curve is often called the breakthrough curve. The actual shape of the breakthrough curve is an indication of the kinetics of hydrogen absorption of the packing material. A steep rise of the curve indicates favorable kinetics for hydrogen separation. Hydrogen absorption by metal hydride is an exothermic reaction. A thermocouple located in the column can measure the temperature peak indicating the location of the absorption front at a given time. Typical breakthrough curve and temperature peak is shown in Figure 6 . This kind of data may be used to compare separation efficiencies and to design separation columns.

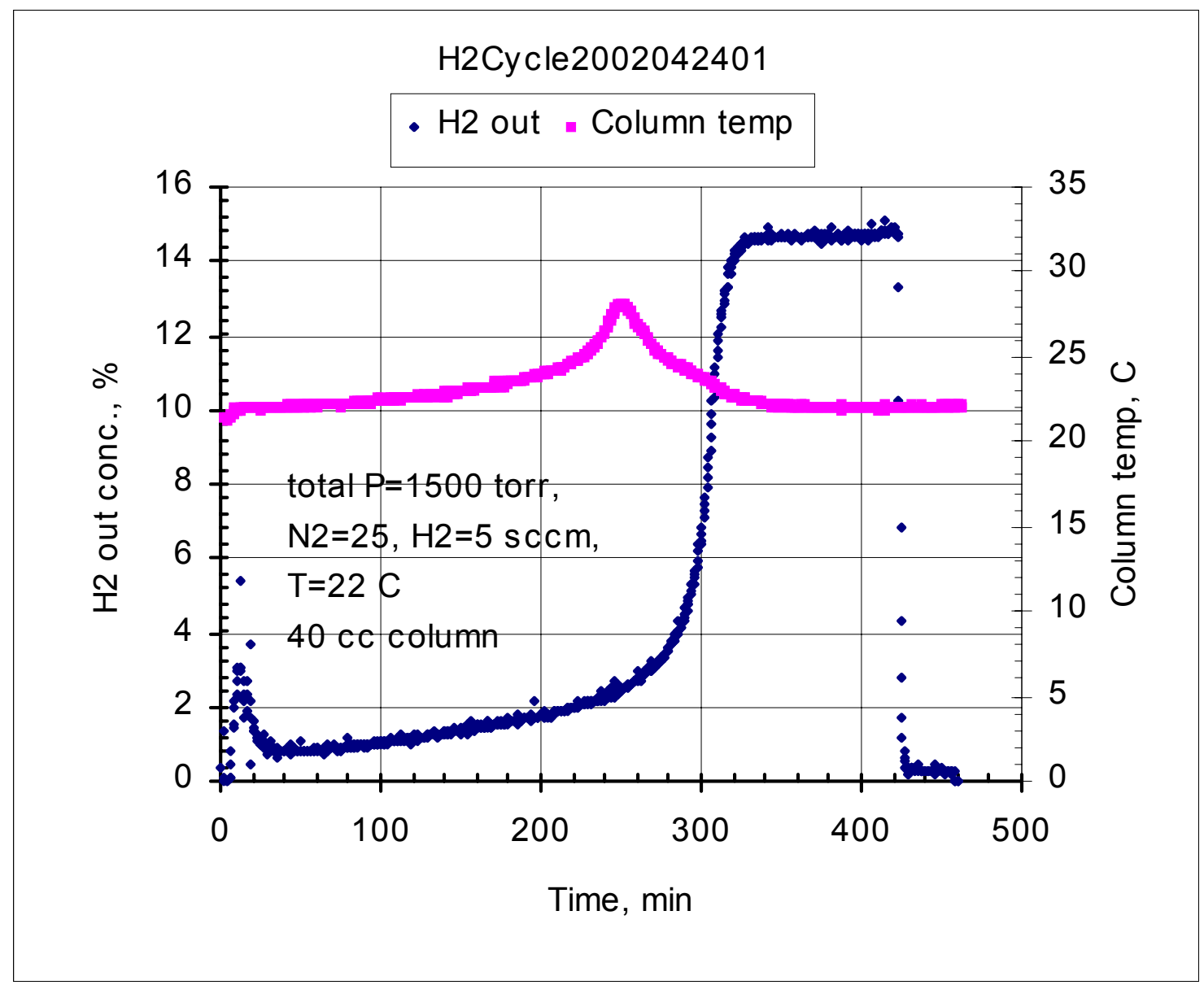

Figure 6. Breakthrough curve of hydrogen absorption by encapsulated metal hydride packed column.

The efficiency of hydrogen removal can be shown by the difference in the amounts of hydrogen entered the column and the amounts of hydrogen left the column as a function of time. For a typical run the results show that about $95 \%$ of the hydrogen entering the column is absorbed continuously until the column is saturated. See Figure 7. 
For typical regeneration, the column is purged with nitrogen and is heated up to about $100{ }^{\circ} \mathrm{C}$ at the same time. The hydrogen concentration at the exit stream is measured by the TCD. From this concentration data the partial pressure of the hydrogen can be calculated. This pressure is a measurement of the hydrogen that can be collected if an evacuation pump is applied. The data in Figure 8 show that about $1 / 2$ of the hydrogen can be recovered at 800 torr, and more than $95 \%$ can be recovered at 100 torr.

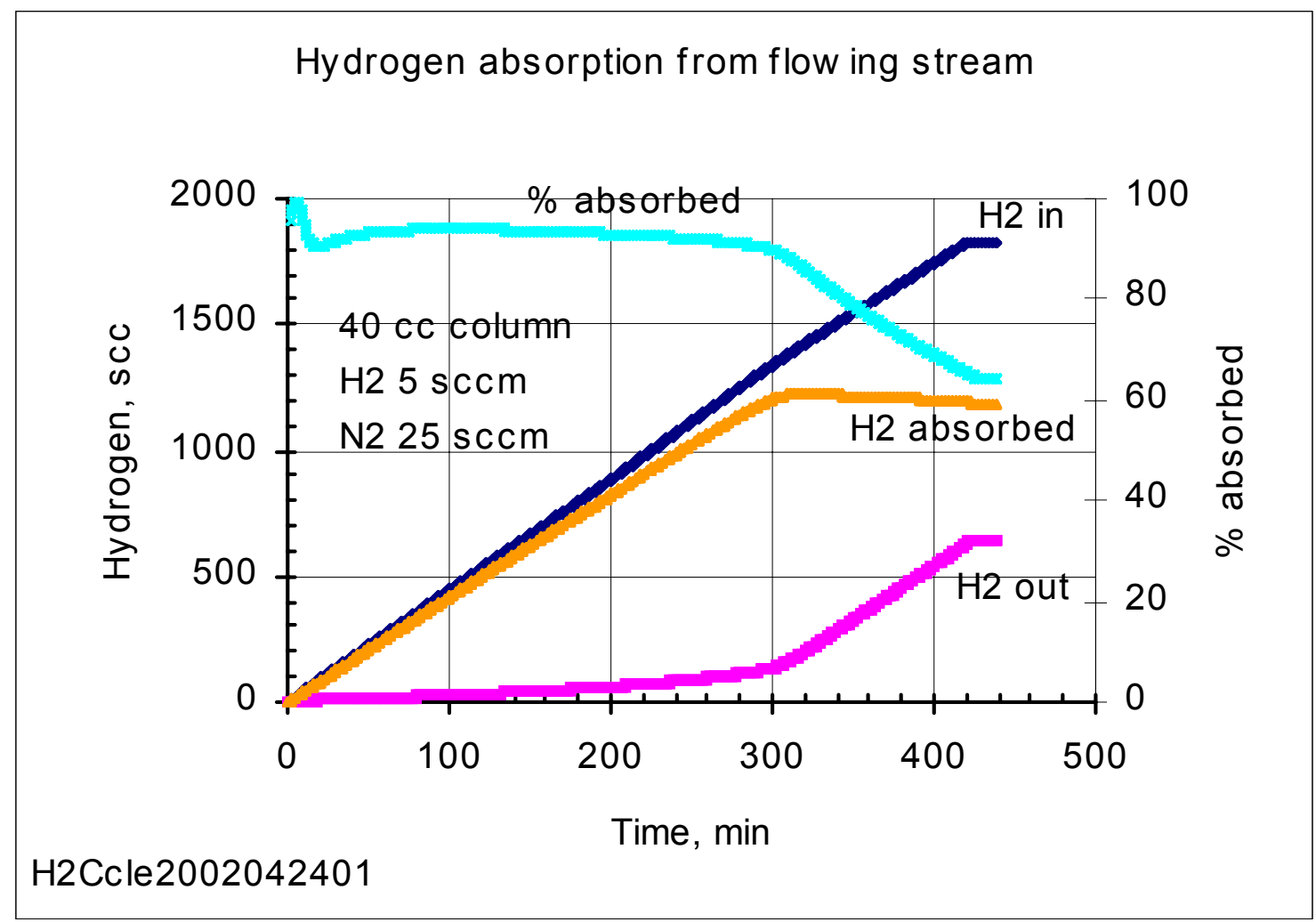

Figure 7. Hydrogen removal from a flowing stream is about $95 \%$.

\section{Summary}

Metal hydride powders can be encapsulated in a porous silica matrix using a sol-gel method. The encapsulated metal hydride retains its hydrogen absorption property with increased resistance to reactive impurities. Granules of encapsulated composite can withstand hydrogen absorption/desorption cycles without producing fines. This makes them applicable in packed separation columns. Hydrogen recovery from a nitrogen stream has been demonstrated in a laboratory column with the encapsulated metal hydride. Hydrogen recovery from other gas streams such as $\mathrm{CH}_{4}, \mathrm{CO}_{2}$ and that containing $\mathrm{CO}$ has been planned and will be tested. Encapsulated metal hydride is suited for hydrogen recovery from low concentration streams that will be needed in a hydrogen economy. 


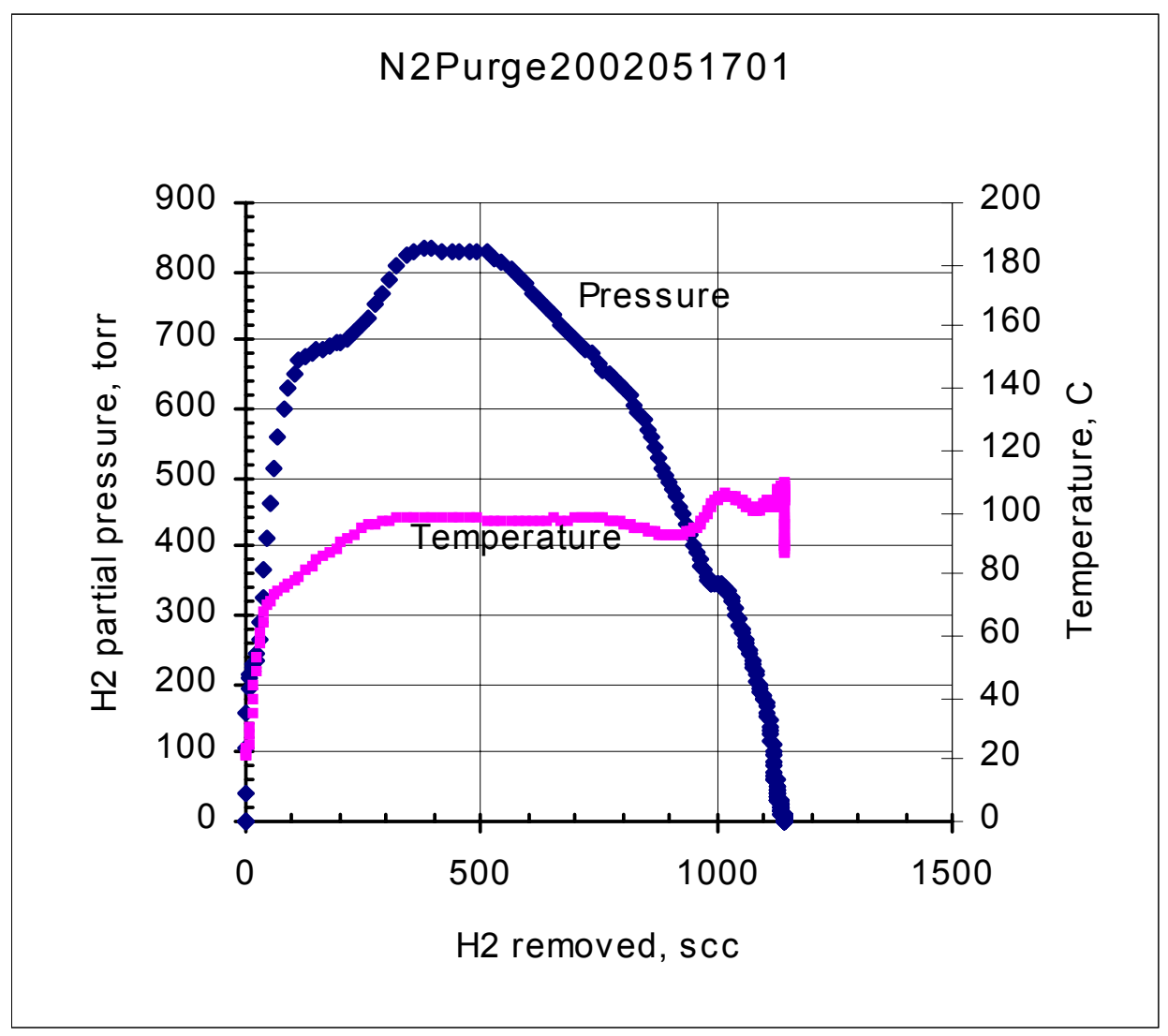

Figure 8. Hydrogen recovery from the column.

Reference:

[1] J. J. Sheridan III et al, Journal of the Less-Common Metals, 89 (1983) 447-455.

[2] X.-L. Wang et al, Journal of Alloys and Compounds 231 (1995) 860-864. 